\title{
THE DEMAND FOR KEROSENE AND PER CAPITA INCOME IN ETHIOPIA ${ }^{1}$
}

\author{
Elias Mulugeta ${ }^{2}$
}

\begin{abstract}
The demand for kerosene is growing at the rate 5.6\% per annum. Per capita income and population growth are determining factor that can directly affect the demand for household kerosene fuel in Ethiopia. Kerosene consumption is a log log (double logarithm) non linear function of per capita income through time. It is an ideal demand function. The demand for total kerosene consumption is income elastic and the elasticity coefficient is 8.9 in Ethiopia. This indicates that as income increase kerosene consumption increases, a $1 \%$ increase in per capita income will result in $8.9 \%$ increase in total kerosene consumption, i.e. more than a proportionate increase in demand for kerosene. Urban population is a limiting factor for kerosene consumption in Ethiopia. Urban population is growing rapidly. It is estimated that urban population growth at the rate of $4.1 \%$ per annum during the last 15 years.
\end{abstract}

The study tries to forecast demand for kerosene in 2005-2020. Between 1991-2004, household kerosene demand has been growing at the rate of $5.9 \%$ per annum. Forecasting of the demand for kerosene was based on econometric model. The total urban kerosene demand will be 275,470 $\mathrm{m}^{3}$ in 2006, 346,900 $\mathrm{m}^{3}$ in 2010, 457,190 $\mathrm{m}^{3}$ in 2015 and $594,166 \mathrm{~m}^{3}$ in 2020. The Addis Ababa kerosene demand will be 111,420 $\mathrm{m}^{3}$ in 2006, 134,930 $\mathrm{m}^{3}$ in 2010, 168,400 $\mathrm{m}^{3}$ in 2015 and 204,030 $\mathrm{m}^{3}$ in 2020. This study attempts to overview the demand and supply of household fuels in Ethiopia, in general, and commercial fuels, in particular. We will also compare and contrast nominal prices and the amount of energy per unit cost for important fuels. Even though fuel wood has the lowest quality, it is the cheapest energy source among household fuels and that is why poor households preferred to consume it. Kerosene becomes the most expensive fuel than wood as well as charcoal. We look at the demand elasticity of price and income and analyse the effect of change in price and income on consumption of different household fuels.

Key words: Kerosene demand; per capita income; income elastic; population growth; kerosene demand projection;

\footnotetext{
${ }^{1}$ The final version of this article was submitted in November 2006.

${ }^{2}$ International Livestock Research Institute, P.O. Box 5689, Addis Ababa, Ethiopia
} 


\section{Background}

The study provides a brief overview of kerosene demand in Ethiopia. The country has experienced many changes in its energy consumption patterns both in quantity and qualitative terms since the introduction of kerosene as household fuel. This can be explained using two factors. The first factor is based on population growth and demographic changes in household size and age groups. The second factor is the change per capita income and in economic development. Household kerosene energy consumption is expected to increase as economy develops, rise in per capita income and change in life style. The pattern of household energy consumption represents the stage of economic development. In Ethiopia, energy consumption per capita is much lower than many developing countries. As economy develops, more and clean energy is consumed. It is natural for people to pursue a better life, which often means improve their proper cooking, heating and lighting source of energy to modern commercial fuels.

In addition to population growth and economic development, household also change their choice of energy source due to different reasons, such as rise in energy price, availability and convenience. Energy consumption of individuals also increases with increase in disposable income. Households with better income consume greater quantity and more convenient forms of energy.

The recent rise in kerosene price is the largest shift in price which have occurred during the last 20 years, before kerosene was not that much popular as household energy fuel in Ethiopia. Recently kerosene price has increased by 37 percent over the past few years to 4.12 (Ethiopian Birr) ETB per litre from its recent price of 3.00 ETB per litre. The increase was made in two consecutive periods. Initially it has increased by 5 percent and in the second round adjustment was made by increasing $32 \%$ to 4.12 ETB per litre on August 27, 2006.

The first impact on the households is it reduces real income. Further higher inflation rate will lower the purchasing power of the poor who have fewer instruments to hedge against the kerosene price increase. The biggest impact will be on poor households, which used kerosene for cooking and lighting. It is not well known whether the pressure of higher price will lead to significant switch in energy consumption from kerosene to biomass (fuel wood, crop residue and dung). High energy prices should be viewed as a signal to reduce the heavy reliance on kerosene and make use of alternate clean energy resources. And more substitutions are likely if it continues its upward shift. 
The primary factors which influence modern energy consumption in Ethiopia are levels of per capita income and population growth. However, a significant change in kerosene consumption has occurred as a result of change in urbanization and population growth.

\subsection{Objective of the study}

The main aim of this study is to forecast the demand for urban kerosene consumption based on per capita income. Most of the data used in subsequent analysis is based on population census and population forecasted by Central Statistics Authority (CSA). Based on population growth, it is estimated that kerosene demand in Ethiopia will grow at the rate of $5.6 \%$ annually from 2006-2020.

The study does not take into account the use of commercial energy mix. However, local production of alternative fuels like ethanol has been recommended as a substitute fuel for kerosene.

\subsection{Methodology}

Kerosene demand has been projected using econometric models. Econometric models are based on observed relationships between actual kerosene consumption and explanatory variables. Time series of kerosene consumption has been sourced from Ethiopian Petroleum Corporation (EPC).

Kerosene consumption is a log log (double logarithm) non-linear function of per capita income through time as indicated above. Such fitting represents higher explanation power of the demand on population. The kerosene demand extrapolation equations are presented below for urban and Addis Ababa, respectively.

$$
\begin{aligned}
& \operatorname{Ln}(\text { KeroUrban })_{t}=a+b \operatorname{Ln}(\text { percapitai ncome }) \\
& \operatorname{Ln}(\text { KeroAA })_{t}=c+d \operatorname{Ln}(\text { percapitai ncome })
\end{aligned}
$$

where, a, b, c and d are parameters to be estimated by the model. Ln is the natural logarithm function, $t$ is time, Kerourban and KeroAA is the urban and Addis Ababa kerosene household consumption, and per capita income in urban and Addis Ababa population, respectively. The above extrapolation equations explain that as per capita income increases the demand for kerosene increases. 
In forming econometric model, macro-economic indictors like Gross Domestic Product (GDP) per population has been taken to be the primary explanatory variable. An increase in per capita income will lead to an increase in the demand for kerosene. Urban population structure reflects the degree of urbanization. Similarly an increasing rate of urbanization will lead to an increase in demand for kerosene. These variables are technically referred as robust variables. They indicate the pace and composition of economic progress. They also capture the underlying structural changes in the various economic sectors of the economy. The demand for kerosene projection has been developed based on assumption regarding the future path of the Ethiopia economy. In the extrapolation, GDP is assumed to grow at the rate of $6 \%$ per annum.

\section{Overview of household energy consumption in Ethiopia}

The most striking feature of the Ethiopian energy sector is over consumption of low grade traditional energy sources and under consumption of high quality modern fuels (electricity, liquid petroleum gas (LPG) and kerosene). Despite the poor documentation on production and consumption of wood fuel, (EFAP 1994) estimated that wood provided $78 \%$ while dung and crop residue provided $16 \%$ of household energy requirement in 1992. The country's fuel energy is heavily dependent on traditional biomass. Biomass provides more than $94 \%$ of the total energy consumption in the country and only $6 \%$ of household energy is dependent on commercial fuels in 1992.

Household fuel consumption is significantly dependent on location. There is a difference in energy consumption between rural and urban households. In urban areas energy expenditure constitutes a significant portion of the total household expenditure. Growth in kerosene consumption is essentially linked to urban population growth rather than rural population. Almost $95 \%$ of kerosene consumption is in urban areas. EFAP (1994) estimated that kerosene replaced woody biomass mainly for cooking in urban areas, which used to be only $8 \%$ in 1992 (see Table 1). Urban households still rely on non-commercial energy, biomass fuels. Wood provided $62 \%$ while dung and crop residues provided $27 \%$ of the energy requirement in 1992. Electricity constituted $3 \%$ of the household energy requirement in 1992 and it is mainly used for household light energy.

The forecast of urban household energy use in 2014 is very surprising; almost $35 \%$ of biomass, which is low grade household energy (wood, dung and crop residue) will be replaced by commercial energy sources. Kerosene and electricity are grouped under modern energy. The share of kerosene was the least among other energy sources in 
1992, however, its demand has expected to rise tremendously and replace lower grade energy sources in the future. Kerosene consumption will reach $20 \%$ of the total energy consumption and the use of electricity will grow to $15 \%$ in 2014 . There is a very significant achievement in terms of substituting low grade traditional energy sources to more modern and commercial energy sources. This indicates that as urbanization increases kerosene consumption is growing faster than biomass.

Rural households rely largely on non-commercial energy, bio-fuels. EFAP (1994) estimated that in rural areas fuel wood provided $66 \%$ while dung and crop residues provided 34\% of energy requirement in 1992 (see Table 1). The importance of biomass energy in rural sector will continue at least in the near future and it is unlikely to provide significant amount of modern energy to rural areas of Ethiopia. It is projected that wood fuel provided $68 \%$ while dung and crop residues provided $20 \%$ of the energy required in rural areas in the year 2014. The percentage consumption of fuel wood forecast as well as commercial fuels in 2014 does not show much change in rural areas, however, there will be a significant increase in the consumption of modern fuels and increase in power investment for a new installation of electricity in rural areas. Projected consumption of modern energy in rural areas is still very low compared to biomass; in the year 2014 the consumption of electricity and kerosene is $5 \%$ and $2 \%$, respectively. The forecast of kerosene and electricity in rural areas is mainly used for light energy.

Table 1: Household fuel energy consumption in Ethiopia

\begin{tabular}{lcccc}
\hline \multirow{2}{*}{ Source of energy } & \multicolumn{2}{c}{ Urban (\%) } & \multicolumn{2}{c}{ Rural (\%) } \\
\cline { 2 - 5 } & $\mathbf{1 9 9 2}$ & $\mathbf{2 0 1 4}$ & $\mathbf{1 9 9 2}$ & $\mathbf{2 0 1 4}$ \\
\hline Wood /charcoal & 62 & 42 & 66 & 68 \\
Dung & 16 & 8 & 20 & 13 \\
Crop residue & 11 & 5 & 14 & 7 \\
Electricity & 3 & 15 & 0 & 5 \\
Kerosene & 8 & 20 & 0 & 2 \\
Other & 0 & 10 & 0 & 5 \\
Total & 100 & 100 & 100 & 100 \\
\hline
\end{tabular}

Source: EFAP (1994).

The household sector accounts for $90 \%$ of overall energy consumption in Ethiopia. This indicates that Ethiopia is at low level of industrial development and country's industrial kerosene consumption is still lower than the household energy consumption for kerosene. Strong correlation exists between energy consumption and per capita income as well as population growth, the development of infrastructure and the availability of biomass energy in the area. 


\section{$2.1 \quad$ Biomass fuel}

Almost more than $95 \%$ of the fuel wood is consumed in rural areas. It is estimated that total per capita energy consumption is $2.1 \mathrm{~kg}$ of wood fuel equivalent per person per day (CEPPE 1987). In 1990, Amibara Irrigation Project II estimated similar result and consumption of fuel wood was $15 \mathrm{~kg} /$ household per day or $2.5 \mathrm{~kg} / \mathrm{person}$ per day.

About 24 million $\mathrm{m}^{3}$ of wood is produced annually of which $90 \%$ is used for household fuel consumption and only $10 \%$ is used for industrial and building purposes (EFAP 1994). Fuel wood is mainly consumed for cooking and heat. In addition to these uses, there are also villages where fuel wood is also used as light. Such villages let fuel wood burning continuously during the night to avoid darkness. Per capita consumption of fuel wood differs from place to place both in rural and urban. The average estimated consumption of fuel wood per household was $440 \mathrm{~kg}$ per annum Consumption of firewood energy in the household mainly depends on household size. There is a high positive correlation between household size and total domestic fuel use. Fuel wood consumption for cooking and making 'injera' is very common in Ethiopian cities and peri-urban areas. In big towns where electricity is available, significant households use kerosene for cooking and electricity for making 'injera' substituting fuel wood.

The projection of sustainable fuel wood supply from all forest types is 8.8 million $\mathrm{m}^{3}$ without any intervention but the projected supply will reach 21.8 million with intervention scenario by 2014 (EFAP 1994). The woody supply from trees outside forests is mainly fuel wood for the rural population, wood for fencing and construction. The supply of fuel wood from farm homesteads was estimated at 80 thousand tonnes per year (FAO 2001).

The available supply of forest does not exceed more than 14 million hectares in Ethiopia. From this about 5 million hectares is shrub land and other 5 million hectares is bush land. Wood land and plantation cover only 2000 and 255 hectares, respectively (EFAP 1994).

The wood supply from woodlot land mainly derived from two major sources, i.e. farm forestry and the woody vegetation patches. The average volume per hectare for closed high forest is estimated to range from $30-120 \mathrm{~m}^{3}$ per hectare and up to $50 \mathrm{~m}^{3}$ per hectare for open forest. The annual incremental yield from all available forest was estimated at 14.4 million $\mathrm{m}^{3}$ while the demand was 47.7 million $\mathrm{m}^{3}$ for the year 1992 (EFAP 1992). 
Fuel wood shortage is becoming a serous problem in Ethiopia. The main cause of this shortage is population pressure. In 1984 the population of Ethiopia was 42.2 million and growing at 2.95 per annum. In 1990 it was estimated at 50.6 million out of which $89 \%$ lived in rural areas. It grew to 61.7 million in 1999 out of which $85 \%$ lived in rural areas (CSA 1998). Fuel wood collection took an hour or two a generation ago while today it takes the whole day (Eckholm 1975). The forest resource that was used to cover $16 \%$ of the land area in the early 1950 s were reduced to $3.6 \%$ in the early 1980 s and further declined to $2.7 \%$ in the early 1990s (FAO 2001). FAO (2001) compiled forest assessment report and indicated the forest resource available for fuel wood supply remains only 14 million hectares. The total area of natural forest is expected to decline at the rate of 62 thousand hectares per year (FAO 1990).

This condition can be easily described using the trend observed between fuel wood supply and demand. The fuel wood demand and supply projections documented by EFAP (1994) indicated that the demand for fuel wood was 58 million $\mathrm{m}^{3}$ whereas the supply was 11 million $\mathrm{m}^{3}$ indicating the deficit was more than four times the supply. The same document had shown a deficit projection of 55 million $\mathrm{m}^{3}$ in 2004, 65 million $\mathrm{m}^{3}$ in 2008 and 80 million $\mathrm{m}^{3}$ in 2014 . The projection made for the year 2020 indicated that the demand will reach to 100 million $\mathrm{m}^{3}$ against a supply projection of 7.7 million $\mathrm{m}^{3}$ envisaging a deficit of 92.3 million $\mathrm{m}^{3}$ (EFAP 1994).

The wood scarcity is a manifestation of much deeper and rooted problem of poverty. Actually, firewood is an important input to household consumption from which household cannot easily substitute (Loughram and Pritchett 1996). If fuel wood is substituted by dung and crop residue, there is a trade off between using crop residue and dung as inputs for agriculture and burning as a fuel. This alternative energy sources may have substantial financial costs as well as opportunity costs. Dung is used for cooking in rural parts of Ethiopia but it is also an important source of fertilizer, and using it for fuel can have adverse effects on soil fertility. That is why such energy sources will vanish in their energy use through time. If wood is substituted by modern and commercial energy, poor households may not afford such fuels.

\subsection{Commercial household fuels in Ethiopia}

Modern household fuel consumption in Ethiopia is dominated by kerosene. This change in energy consumption pattern can be more easily understood if one looks closely at fuel switch by end use. The cooking energy source has gradually changed since kerosene is introduced in Ethiopia. With rapid urbanization, kerosene as household fuel has been expanded rapidly and now it dominates commercial cooking fuel. 
In Ethiopia, the major part of commercial energy is consumed in urban areas. The per capita modern fuels consumption in Ethiopia is about 0.02 tonnes of oil equivalent (TOE) or $20 \mathrm{~kg} / \mathrm{year}$ (UNDP 1995), among the lowest modern energy consumption in the world. The low level of modern energy consumption is caused by both supply and demand side problems. On the supply side, low electricity generation, shortages in foreign exchange, inefficiency of service providers, imperfections in energy markets and lack of infrastructure are some of the problems. On the demand side, low purchasing power of the poor is the main problem.

A more profound examination of the potential for increasing the consumption of modern fuels requires an understanding of the overall energy demand of urban households. As the population moves from rural communities to increasingly crowded urban cities, their energy use patterns change towards modern fuels (Barnes 1995). Most of the potential additional demand for modern energy in urban households will come from substituting for biomass fuels.

The consumption of commercial energy and the standard of living are positively and non-linearly correlated (Goldenberg and Johannson 1995). This implies that with economic growth, especially at the lower level of development, we expect rapid growth in the demand for commercial energy. Accessibility and affordability of modern fuels will be still in question and affected by costs, especially for poor households.

Many researches indicate that the pattern of urban energy demand generally reflects the prediction from the 'energy ladder' hypothesis that states share of traditional fuels use decreases with economic development while those of modern fuels increase. This implies electricity and kerosene replaces wood as the primary cooking fuels. The three stone fire is abandoned and charcoal and kerosene stoves and LPG cook stoves become the cooking devices of choice. The population growth in urban areas not only triggers changes in the type and form of energy used but also implies a much higher demand for energy. Per capita use of energy increases significantly as the population moves from rural communities to urban (Karekezi 1999).

Energy prices in general and the relative prices of different fuels in particular are important determinants of demand. Prices may be depressed by subsidies. Due to the subsidized prices of electricity and kerosene in Ethiopia, consumption was increased tremendously. Poor households generally expend proportionally more on energy than richer households and hence higher energy costs will have a larger budgetary implication for the poor (Bereket et al. 2002). Compared to the poor, the non-poor households expend relatively more on modern forms of energy and less on traditional forms. 


\subsection{Kerosene}

Kerosene is used as a main source of cooking fuel in urban areas and used as a source of light in rural areas. Ethiopians cook tea, vegetable soup or 'wat' to eat with 'injera', as well as boil water, make coffee and other purpose several times a day. Many urban dwellers cook 'wat' with kerosene or charcoal stove and bake injera on an open fire or electric stove. Kerosene is becoming a primary source of fuel energy for cooking in urban areas although wood and charcoal continue to be widely used.

Daily household energy consumption in Addis Ababa estimated at 63.8 mega joule (MJ) and the daily per capita energy consumption amounts to $11.5 \mathrm{MJ}$ or $0.81 \mathrm{~kg}$ airdried wood equivalent (CEPPE 1985). The frequent use of different fuels in Addis Ababa is presented in Table 3. In 1985, kerosene was used as a backup fuel by $37 \%$ of the household in case fuel wood is not available while wood was used frequently. However, in 1994, the situation became different; kerosene has become a primary source of cooking fuel. Kerosene was used as cooking fuel in $80.2 \%$ of households in Addis Ababa.

The frequent use of charcoal and wood has declined in the same time period. In 10 years period kerosene has displaced $43 \%$ of biomass users and obliged to switch their energy consumption to commercial fuel. This shows a significant growth in supply of kerosene between 1985-1994. Like wise, 10\% of households switched their energy source to electricity. This also leads to a steady growth in demand for electric stove in Addis Ababa.

Table 3: Change in Addis Ababa household energy demand and frequency of use for cooking during 1985 and 1994

\begin{tabular}{lccc}
\hline \multicolumn{1}{c}{ Fuel } & \% use in $\mathbf{1 9 8 5}$ & \% use in 1994 & Difference \\
\hline Kerosene & 37.1 & 80.2 & 43.1 \\
Charcoal & 91.4 & 79.0 & -12.4 \\
Wood & 93.5 & 64.7 & -28.8 \\
Electricity & 21.0 & 31.1 & 10.1 \\
LPG & 13.1 & 9.6 & -3.5 \\
Others & 0 & 2.4 & 2.4 \\
\hline
\end{tabular}

Source: EELPA (1987); EPC (1995).

There is close correlation between income level and energy consumption. A study reveals that poor households are the least consumers of modern energy and shows that total energy increases with income (Sonkona 2005). Households with higher socio-economic status and level of education consume more energy and are better in 
a position to acquire modern energy such as electricity. Energy source serves as an indicator of the level of poverty of the household.

The evolution of kerosene consumption in Addis Ababa is quite interesting. The average per capita household energy consumption was $21.4 \mathrm{MJ}$ in 1978 . Wood was a primary source of fuel in Addis Ababa and it was providing $65 \%$ of fuel consumption in 1978 . Modern fuels were only providing $16.2 \%$. Kerosene was providing quite very low proportion and it was only $6.6 \%$ of energy consumption in Addis Ababa. The average per capita household energy consumption in 1986 dropped to $12.1 \mathrm{MJ}$ after wood fuel has become increasingly unavailable and expensive in Addis Ababa. In 1986, the dominance of biomass fuel is slightly reduced and the introduction of commercial fuels has been increased from the level of $16.2 \%$ to $20.6 \%$ in Addis Ababa (see Table 4). At this time charcoal was a primary source of cooking fuel in Addis Ababa. In 1986, charcoal consumption is slightly higher as compared to kerosene $(17.3 \%$ and $14.3 \%)$. Kerosene took the place of charcoal as primary source of cooking fuel in 1988.

Table 4: Average per capita household energy consumption in Addis Ababa

\begin{tabular}{lcccc}
\hline Fuel type & $\begin{array}{c}\text { Consumption } \\
\mathbf{1 9 7 8 ^ { * }} \\
\text { MJ }\end{array}$ & $\begin{array}{c}\text { Share in \% } \\
\mathbf{1 9 7 8}\end{array}$ & $\begin{array}{c}\text { Consumption } \\
\mathbf{1 9 8 6}^{* *} \\
\mathbf{M J}\end{array}$ & $\begin{array}{c}\text { Share in \% } \\
\mathbf{1 9 8 6}\end{array}$ \\
\hline Biomass & & & & \\
$\quad$ Wood & 13.9 & 64.9 & 4.2 & 34.7 \\
$\quad$ Charcoal & 3.4 & 15.9 & 2.1 & 17.3 \\
$\quad$ Wastes & 0.6 & 3.0 & 3.2 & 26.4 \\
Modern fuels & & & & 14.3 \\
$\quad$ Kerosene & 1.4 & 6.6 & 1.8 & 6.3 \\
$\quad$ Electricity & 0.6 & 2.8 & 0.8 & 0 \\
$\quad$ Others & 1.4 & 6.7 & 0 & 100.0 \\
Total & 21.4 & 100.0 & 12.1 & \\
\hline
\end{tabular}

Source: * CSA (1985); ${ }^{* *}$ CEPPE (1987).

In 1991, kerosene constitutes $46.6 \%$ of household energy demand for cooking in Addis Ababa. The total share of commercial fuels is close to $58 \%$ of energy demand for cooking. Charcoal is the second source of cooking fuel particularly used for coffee making and occupies $22 \%$ of the total energy demand for cooking in Addis Ababa in 1991 (Table 4). Kerosene consumption grew to 48.5\% while electricity for injera making grew to $14.6 \%$ in 1994 . This shows that total substitution effect of commercial fuels for cooking household energy has reached to $63 \%$ in 1994 . The effect of substitution is very fast and the diffusion is much higher in the latter years. 
Kerosene displaced over 455 thousand tonnes of woody biomass in 1992 (EPC 1995). Kerosene's substitution effect grew to over 640 thousand tonnes of woody biomass in 1994, an increase of $50 \%$. Fuel switching is equivalent to yield of 288 thousand $\mathrm{m} 3$ of wood, representing the sustainable yield of 19 thousand hectares of prime eucalyptus plantation. This represents a major source of fuel substitution in urban areas which undoubtedly has reduced pressures on woody biomass in the country side.

Table 5: Change in Addis Ababa household energy demand and use for cooking during 1991 and 1994

\begin{tabular}{lccc}
\hline \multicolumn{1}{c}{ Fuel use } & $\mathbf{1 9 9 1}$ & $\mathbf{1 9 9 4}$ & \% share in 1991 \\
\hline Bio-injera & 147,432 & 183,441 & 15.1 \\
Electric-mitad & 111,137 & 194,024 & 11.3 \\
Charcoal & 215,458 & 248,141 & 22.1 \\
Kerosene & 455,400 & 642,192 & 46.6 \\
Others & 47,130 & 56,342 & 4.8 \\
Total & 976,557 & $1,324,139$ & 100.0 \\
\hline
\end{tabular}

Source: EPC (1995).

This positive environmental effect has been one of the major reasons for importing kerosene and substituting it for domestic use since 1980s. The major rationale underpinning kerosene imports was to offset woody biomass demand and reduce deforestation. Petroleum imports that were close to 142 million ETB in $1991 \mathrm{grew}$ to 1.4 billion ETB in 1996, and climbed to 2.174 billion ETB in 2000. Petroleum import was close to 2.674 billion ETB in 2003. In the beginning of 1990s, Ethiopia spends over USD 20 million per annum on household kerosene compared to USD 3 million in 1986. Kerosene imports for household use continue to rise dramatically and imports represent 125 thousand tonnes which cost over USD 35 million in 1994.

In Ethiopia, the proportion of households which consume kerosene is higher in the middle income class. As income increases to higher level, the consumption of kerosene declines. Electricity accounts for a larger share of energy requirement as income increases. In Ethiopia, Kebede (2001) classified urban households into five income groups and found that $47.7 \%$ of the households were very poor and poor, and control only $15 \%$ of the overall urban household income. On the other hand, $41.2 \%$ of the rich and very rich households controlled up to $77.7 \%$ of the urban household income. Typical activities of the average urban resident is usually more modern and energy intensive than the activities of a rural resident. Consequently, the ongoing rural-urban demographic shift is expected to result in a large increase in modern energy consumption (Karekezi 2002). 
In rural household, kerosene consumption is very low as compared to urban. This is because fuel wood is more available and cheapest source of energy in rural areas. Kerosene is not yet being introduced in countryside as a source of fuel for cooking. However, $73 \%$ of the household use kerosene for lighting, only $0.7 \%$ from electricity and $26.3 \%$ use other traditional lighting mechanism mainly 'Chakma' seed ${ }^{3}$ in the northern part of Ethiopia in 1996.

More options exist in urban areas even for the poor as compared to their rural counterparts. For instance, while the budget share of electricity is the highest for the non-poor; firewood occupies that position for poor households. As a more efficient source of heat compared to firewood, policy may have to take charcoal as an important energy source for urban poor in the short run. Moreover, poor households expand the same amount of their energy budget on kerosene as on charcoal underscores the possibility that kerosene is realistic substitute for biomass fuels even for the poor in urban areas in the long run.

\section{$2.4 \quad$ Electricity}

Electrification is at an infant stage of development throughout the country and largely used in association with larger urban areas for residential use and manufacturing. Only $57.4 \%$ and $2.7 \%$ of urban households used electricity for lighting and cooking in 1996, respectively. While only $0.7 \%$ of rural households used electricity for lighting, none cooked with it. Apart from this inefficiencies, the reliability and availability of existing installed electricity system is very low. However, national figures show considerable regional variation in both supply and consumption demand patterns of electric power. This could be due to the varying demand in the regions and costs of supplying alternative energy sources which also have large influence on the consumption pattern and the level of energy consumption in the regions. Another reason could be the level of investment projects undertaken in the regions.

Electricity is the primary source of light in urban areas. Electricity accounts for a larger share of energy requirement as income increases. Mostly the upper income class consumes electricity for cooking.

More than $98 \%$ of electric power is generated through hydropower energy while $2 \%$ from thermal energy. The main hydropower energy sources are Finchaa power station which accounts for $48.9 \%$ of the total electric power generation and the two Tis Abay stations generate $25.6 \%$, the three Awash stations $10 \%$ and the Melka

\footnotetext{
3. Chakima is a seed of 'Gloziet' tree and used for light purpose in rural areas. The seed contains oil like substance after extraction and has similar characteristics like that of kerosene.
} 
Wakena station 15.5\% (NBE 2002). The supply of hydroelectricity is somewhat constrained by capacity limitations for many years in 1980s and 1990s and supply has now started to increase after 2000.

Table 6: Electric power generation in Ethiopia in 2000-2003

\begin{tabular}{|c|c|c|c|c|c|}
\hline Year & $\begin{array}{c}\text { Electric } \\
\text { power } \\
\left(\times 10^{6} \mathrm{kwh}\right)\end{array}$ & $\begin{array}{c}\text { Urban } \\
\text { population } \\
\left(\times 10^{3}\right)\end{array}$ & $\begin{array}{c}\text { Total } \\
\text { population } \\
\left(\times 10^{3}\right)\end{array}$ & $\begin{array}{c}\text { Kwh per } \\
\text { person } \\
\left(\times 10^{3}\right)\end{array}$ & $\begin{array}{c}\text { Total per } \\
\text { capita } \\
\left(\times 10^{3}\right. \\
\text { kwh/person }\end{array}$ \\
\hline $2000 / 1$ & 1,992 & 9,473 & 54,022 & 200 & 36.8 \\
\hline $2001 / 2$ & 2,130 & 9,886 & 55,458 & 215 & 38.4 \\
\hline $2002 / 3$ & 2,142 & 10,307 & 56,913 & 207 & 37.6 \\
\hline $2003 / 4$ & 2,311 & 10,747 & 58,382 & 215 & 39.6 \\
\hline
\end{tabular}

Source: National Bank of Ethiopia (NBE).

The total electric power supply was 1,992 million kwh in 2000/01 and grew to 2,311 million kwh in 2003/04, indicating $16 \%$ increase in supply between 2000-03. This electric power generation has met only 1.791 million urban households' energy requirement. Per capita modern energy consumption has been increasing over the last few years in Ethiopia and it is expected to increase further as investment in hydropower generation increases in the future. However, the current per capita power generation is very low in Ethiopia compared to other least developing countries. The average per capita power generation is close to 38 thousand kwh/annum per person between 2000-04. If the per capital power generation is calculated only for urban population, it amounts to 209 thousand kwh/annum per person. This is very low compared to other developing countries.

The use of kerosene, wood and charcoal seems to predominate in areas without adequate access to electricity. Introduction of electricity tends to change the energy consumption pattern as demonstrated after connection to electricity, the use of kerosene, wood and charcoal decreased, with the largest drop being in the use of wood because it is also used for cooking injera and lighting.

\subsection{Liquidized petroleum gas (LPG)}

LPG is used mainly for cooking in the urban household. The demand for LPG has declined over the last ten years (1994-2004). This is because LPG is becoming the most expensive cooking fuel in Ethiopia. The supply of LPG also dropped significantly due to decline in demand. The highest total LPG supply was $8,227 \mathrm{~m}^{3}$ in 1994 and 
now dropped to the level of $700 \mathrm{~m}^{3}$ in 2000. Over the same period, LPG demand declined at the rate of $23 \%$ per annum.

Unlike kerosene, the demand for LPG is price elastic for higher income groups. This implies an increase in price would persuade customers to alter their behaviour towards other source of energy. Since the major LPG consumers are higher income group, they switched to electricity.

\section{Household kerosene demand projection}

\subsection{Trend analysis}

Kerosene supply in Ethiopia has more than tripled over the period between 19912004. During the same period kerosene supply ${ }^{4}$ grew at the rate of $6.8 \%$ per annum. The total supply of kerosene was $71,634 \mathrm{~m}^{3}$ in 1991 and has increased to 244 thousand $\mathrm{m}^{3}$ in 2004 . While the international price of kerosene doubled within the last five years, the price of kerosene which was USD $269 / \mathrm{m}^{3}$ in $2002 / 03$ it is USD $418 / \mathrm{m}^{3}$ in 2004/05.

The household sector remains the dominant kerosene consumer in Ethiopia and most of the future demand growth comes from the household sector. Household kerosene demand in Ethiopia has also tripled over the period 1991-2004. Between 1991-2004, household kerosene demand ${ }^{5}$ has been growing at the rate of $5.9 \%$ per annum. The total household demand for kerosene was $100,668 \mathrm{~m}^{3}$ in 1992 and has reached $219,605 \mathrm{~m}^{3}$ in 2004. Non-household consumption of kerosene was insignificant during the period 1991-99 and below 5\% of the total consumption. Major nonhousehold kerosene consumers are construction, agriculture, EELPA and defence sector. We have noticed that non-household kerosene consumption has increased to $10 \%$ during the period 2000-04. This is due to an increased investment in the construction sector. EELPA has also significantly increased kerosene consumption during the last five years. Industry has reduced its kerosene consumption by $80 \%$ and probably it may have been switched its energy consumption to other alternative sources.

The demand for kerosene has significant variation in regions and location appears to be as an important determinant. Only three regions consume $75 \%$ of the total household supply in Ethiopia. Addis Ababa, Central and Eastern part of Ethiopia have

\footnotetext{
${ }^{4}$. Kerosene supply follows an exponential trend and can be represented by a regression equation: $Y=e^{(-}$ $123.1+0.068 t)$, where, $\mathrm{Y}$ and $\mathrm{t}$ are kerosene supply and time, respectively.

5 . Kerosene demand follows an exponential trend and can be represented by a regression equation: $X=e^{(-106.6+0.059 t)}$, where, $X$ and $t$ are kerosene demand and time, respectively.
} 
consumed 40,21 and $14 \%$ of the total household consumption in the period 19961999 , respectively.

Moreover, the regional distribution of kerosene consumption in the country has shown significant shift. Kerosene retail sales across regions show $61.8,17.5$ and $9.8 \%$ of kerosene was consumed in Addis Ababa, Oromia and Southern Nations and Nationalities People (SNNP) in 1992, respectively. In 1996, the share of Addis Ababa declined to $49 \%$.On the other hand, the share of Oromia, Amhara and Southern Peoples' Regions increased to 25.7, 11.6 and 11.5\%; respectively, in 1996.

The supply of household kerosene has been growing at the rate of $4.9 \%$ per annum in the last 15 years in Addis Ababa. Kerosene supply has almost doubled in the period 1991-2004. The available supply was only $41,572 \mathrm{~m}^{3}$ in 1991 . It grows to close to 98 thousand $\mathrm{m}^{3}$ in 2004 . The trend analysis shows the supply of kerosene has been close to $60 \%$ of the total household supply in early 1990s and has slowly dropped to $40 \%$ in late 1990 s. Indicating the share of other regions has increased significantly.

Available kerosene supply in central Ethiopia has shown significant growth in the last 15 years. Kerosene supply was close to $15 \%$ of the total household supply in 1991 and has slowly grown to $22 \%$ in 1998 . On the average, kerosene supply in central Ethiopia accounts for $21 \%$ of the total household supply in the period 1996-99. The supply of household kerosene has been growing at the rate of $8.6 \%$ per annum in the last 15 years. Kerosene supply is estimated to be $51,200 \mathrm{~m}^{3}$ in 2004 .

Available kerosene supply in Eastern Ethiopia has also shown significant increase in 1991-2004. The supply of household kerosene has been growing at the rate of $9.5 \%$ per annum in the last 15 years. The supply was close to $5.8 \%$ of the total household supply in 1991 and has slowly grown to $15 \%$ of the total supply in the late 1990s. On average, kerosene supply in Eastern Ethiopia accounted for $14 \%$ of the total household supply between 1996-99. Kerosene supply has reached the level of 34 thousand $\mathrm{m}^{3}$ in 2004.

\subsection{Household kerosene demand projections}

The total urban kerosene consumption is divided into household and non-household consumption. The total household kerosene consumption accounts for almost 9099\% during 1991-2004 depending on a particular year. The highest proportion of kerosene consumption was in 1997 which was $99.2 \%$ of the total consumption and the lowest was in 1998 and amounts to $90 \%$. 
The demand for kerosene is highly correlated with urban population. The rate of urban population growth in Ethiopia is higher than the national population growth. This rapid growth in the urban population has major implications on the consumption of energy, particularly modern energy. The total kerosene demand projection is highly dependent on urban population rather than rural. This is because rural population consumes kerosene only for light and the amount of kerosene consumption for light purpose is less than $5 \%$ of the total consumption. Therefore we only extrapolate the projection of household consumption particularly used for cooking in urban areas.

The population of Ethiopia is growing fast at the rate of 3.0\% per annum and reached over 72 million in 2003. The urban population alone is expected to reach over 21 million in 2020 from the current 11.6 million. There has been a change in the annual population growth rate from $2.18 \%$ between 1955 and 1960 to $2.43 \%$ between 1975 and 1980. Even if it is not included in our model, income, prices, and household size, other socio-economic characteristics of households may also affect the demand for kerosene. Habtamu (2001) analysed determinants of kerosene consumption in Ethiopia and shows that family size of the household, education level of the household head and electricity consumption affected kerosene consumption and these factors were positively correlated with kerosene consumption, both at the national and urban level scenarios.

The result of kerosene demand regression is presented in Table 7. A regression was fitted based on kerosene supply data collected from Ethiopian Petroleum Corporation (EPC) and per capita income. The specification of the demand equations is nonlinear and log log function as many literatures indicated. Both Addis Ababa and urban demand regressions are well behaved and the proportion of explained variation or coefficient of determination $\left(R^{2}\right)$ is high: 0.88 and 0.75 for Addis Ababa and urban demand regressions respectively. The $t$-value for per capita income demand elasticity coefficients is highly significant at $99 \%$ confidence probability. The standard errors of the coefficients are very small and indicating reliable.

Table 7: Regression results of kerosene demand in urban and Addis Ababa

\begin{tabular}{lccccc}
\hline \multicolumn{1}{c}{ Variables/ } & Coefficients & Std error & t-value & Significance & $\mathbf{R}^{2}$ \\
\hline Urban & & & & & \\
Constant & -48.3 & 15.3 & $-3.2^{* \star \star}$ & & \\
LN (Per capita income) & 8.9 & 2.3 & $3.9^{\star \star *}$ & 0.002 & 0.75 \\
Addis Ababa & & & & & \\
Constant & -38.2 & 7.7 & $-5.0^{* \star \star}$ & & \\
LN (Per capita income) & 7.3 & 1.1 & $6.4^{* \star *}$ & 0.000 & 0.88 \\
\hline
\end{tabular}

${ }^{*}$ Significant at $1 \%$ probability level. 
The projection and extrapolation of kerosene was done based on the CSA urban population projection from 2005-2020. There is a difference in growth rate of urban population from town to town depending on the rate of urbanization. The rate of growth of total urban population growth is less than the Addis Ababa population. In general, the urban population has grown on the average at the rate of $2.7 \%$ while Addis Ababa population has grown at the rate of 4.1\% per annum during 1991-2005. The projection of household demand for kerosene for Addis Ababa has computed separately from the total urban towns because of their difference in population growth.

Kerosene consumption is a log log (double logarithm) non linear function of per capita income through time as indicated below. Such fitting represents higher explanation power of the demand on population. The kerosene demand extrapolation equations are presented below for urban and Addis Ababa, respectively.

$$
\begin{aligned}
& \operatorname{Ln}(\text { KeroUrban })_{t}=-48.3+8.9 \operatorname{Ln}(\text { percapitai } n c o m e) \\
& \operatorname{Ln}(\text { KeroAA })_{t}=-38.2+7.3 \operatorname{Ln}(\text { percapitai ncome })
\end{aligned}
$$

Where, $L n$ is the natural logarithm function, $t$ is time, kerourban and KeroAA is the urban and Addis Ababa kerosene household consumption, and per capita income. The above extrapolation equations explain that the demand for kerosene is log log function of population and as population increases the demand for kerosene increases, correspondingly. The demand for total kerosene in Ethiopia is income elastic and the elasticity coefficient is 8.9 . This indicates that $1 \%$ increase in per capita income will result in $8.9 \%$ increase in total kerosene consumption in Ethiopia, i.e. more than a proportionate increase in demand for kerosene. The demand for kerosene in Addis Ababa is also income elastic. The elasticity of demand for kerosene is 7.3 and $1 \%$ increase in Addis Ababa population will result in $7.3 \%$ increase in kerosene consumption. This shows that the major consumption of kerosene is Addis Ababa. Such result can be confirmed by calculating the exponential growth rate of kerosene consumption in Addis Ababa and urban areas as a whole. The exponential growth rate of the demand for kerosene in urban areas is $5.9 \%$ whereas the growth rate of the demand for Kerosene in Addis Ababa is $4.9 \%$ per annum.

Total urban and Addis Ababa kerosene demand projection has conducted based on EPC kerosene supply data and CSA population projection. The result of projection estimate is presented in Table 8 . The total urban kerosene demand will be 275,472 $\mathrm{m}^{3}$ in 2006, 346,902 $\mathrm{m}^{3}$ in 2010, 457,190 $\mathrm{m}^{3}$ in 2015 and $594,166 \mathrm{~m}^{3}$ in 2020. 
The predicted kerosene demand is quite impressive in terms of its accuracy and reliability. The total Addis Ababa kerosene demand will be $111,416 \mathrm{~m}^{3}$ in 2006 , $134,929 \mathrm{~m}^{3}$ in $2010,168,393 \mathrm{~m}^{3}$ in 2015 and $204,028 \mathrm{~m}^{3}$ in 2020.

Table 8: Ethiopian urban and Addis Ababa household kerosene demand projections for 2005-2020 $\left(\mathrm{m}^{3}\right)$

\begin{tabular}{ccc}
\hline Year & Urban & Addis Ababa \\
\hline 2005 & $259,854.4$ & $106,000.8$ \\
2006 & $275,472.0$ & $111,416.2$ \\
2007 & $291,991.0$ & $116,942.0$ \\
2008 & $309,403.6$ & $122,709.6$ \\
2009 & $327,733.4$ & $128,725.8$ \\
2010 & $346,902.3$ & $134,928.6$ \\
2011 & $367,066.5$ & $141,180.7$ \\
2012 & $388,041.5$ & $147,834.5$ \\
2013 & $410,055.3$ & $154,540.8$ \\
2014 & $433,097.2$ & $161,442.9$ \\
2015 & $457,190.4$ & $168,393.2$ \\
2016 & $482,284.1$ & $175,310.0$ \\
2017 & 508511.4 & $178,540.9$ \\
2018 & $535,782.4$ & $189,643.1$ \\
2019 & $564,466.9$ & $196,821.6$ \\
2020 & $594,166.1$ & $204,027.8$ \\
\hline
\end{tabular}

Source: Based on extrapolation and regression results.

We have also able to project regions kerosene demand for 2005-2020 based on regions' kerosene supply information obtained from EPC in the period 1991-2000. This result has presented in Table 9. Such projection could have been improved much better if current information on regions' supply of kerosene and GDP forecast data were available. Despite lack of current information on regional consumption, kerosene demand projection for regions are quite remarkable in terms of its consistency with total urban and Addis Ababa demand figures. It is also quite important information for business decision making in the future. Generally, the central part and Eastern regions should be given the highest priority next to Addis Ababa for kerosene distributions and investment. 
Table 9: Regions household kerosene demand projections for 2005-2020

\begin{tabular}{cccccc}
\hline \multirow{2}{*}{ Year } & \multicolumn{5}{c}{ Kerosene demand projections in regions inm ${ }^{3}$} \\
\cline { 2 - 6 } & Central & Eastern & Southern & Northern & Western \\
\hline 2005 & $54,569.4$ & $36,379.6$ & $25,985.4$ & $20,788.3$ & $18,189.8$ \\
2006 & $57,849.1$ & $38,566.1$ & $27,547.2$ & $22,037.8$ & $19,283.0$ \\
2007 & $61,318.1$ & $40,878.7$ & $29,199.1$ & $23,359.3$ & $20,439.4$ \\
2008 & $64,974.8$ & $43,316.5$ & $30,940.4$ & $24,752.3$ & $21,658.3$ \\
2009 & $68,824.0$ & $45,882.7$ & $32,773.3$ & $26,218.7$ & $22,941.3$ \\
2010 & $72,849.5$ & $48,566.3$ & $34,690.2$ & $27,752.2$ & $24,283.2$ \\
2011 & $77,084.0$ & $51,389.3$ & $36,706.7$ & $29,365.3$ & $25,694.7$ \\
2012 & $81,488.7$ & $54,325.8$ & $38,804.1$ & $31,043.3$ & $27,162.9$ \\
2013 & $86,111.6$ & $57,407.7$ & $41,005.5$ & $32,804.4$ & $28,703.9$ \\
2014 & $90,950.4$ & $60,633.6$ & $43,309.7$ & $34,647.8$ & $30,316.8$ \\
2015 & $96,010.0$ & $64,006.7$ & $45,719.0$ & $36,575.2$ & $32,003.3$ \\
2016 & $101,279.7$ & $67,519.8$ & $48,228.4$ & $38,582.7$ & $33,759.9$ \\
2017 & $106,787.4$ & $71,191.6$ & $50,851.1$ & $40,680.9$ & $35,595.8$ \\
2018 & $112,514.3$ & $75,009.5$ & $53,578.2$ & $42,862.6$ & $37,504.8$ \\
2019 & $118,538.1$ & $79,025.4$ & $56,446.7$ & $45,157.4$ & $39,512.7$ \\
2020 & $124,774.9$ & $83,183.3$ & $59,416.6$ & $47,533.3$ & $41,591.6$ \\
\hline
\end{tabular}

Source: Based on extrapolation and regression results.

\section{3 kerosene price and price elasticity}

All fuels own-price elasticities are negative except that for LPG. The demands for firewood, charcoal and kerosene are price elastic, the one for charcoal being with the highest value. The demand for crop residue, dung cakes and electricity is inelastic. The higher price elasticity for traditional fuels like firewood and charcoal imply that their demand will significantly decline if their prices rise. Rise in the price of kerosene can lead to significant declines in consumption because of the high price elasticity. An increase in the price of traditional fuels is usually considered as one important reason pushing households towards the use of modern fuels. Cross-price elasticities indicate that an increase in the prices of firewood implies increase in the demand for electricity while that of charcoal does not affect it.

Bereket et al. (2002) own-price elasticities of firewood and charcoal are high implying that the demand for them will significantly decline with a rise in their prices. But the demand for electricity is price inelastic. This implies electricity price increase will not change consumers' behaviour. The recent increase in electricity tariff was not drastically decrease the demand for electricity. The computed cross-price elasticities indicate that firewood and electricity are substitutes for each other while kerosene 
and electricity are complementary. The substitution between electricity and firewood is mainly explained by fuel used for injera preparation.

We must have a fair understanding of the substitutability and complementarities of modern and biomass fuels, in order to gauge the potential for the expansion of the former. The main factors influencing demand for fuel are income, own price and cross-price elasticities. Bereket et al. (2002) a 1\% increase in the price of kerosene decreases the consumption of charcoal and electricity by $0.05 \%$ and $0.84 \%$, respectively and increases that of firewood by $1.14 \%$. This indicates that kerosene is a substitute fuel for firewood and implies that households move mainly towards firewood; a percentage increase in the price of kerosene increases mean household firewood expenditure by ETB 2.00 Bereket et al. (2002). A removal or decrease of kerosene subsidy implies increased demand mainly for firewood. The argument for keeping the subsidy on kerosene to arrest deforestation by suppressing demand for firewood gives sense in this context. But the rise in the price of kerosene will increase that of charcoal and depress the demand for electricity; a percentage increase in price of kerosene decreases mean household expenditure on electricity by ETB 1.02. A $1 \%$ increase in the price of electricity increases the demand for firewood by $0.36 \%$ while decreasing that of charcoal and kerosene by $0.23 \%$ and $2.14 \%$, respectively. In terms of the absolute magnitudes of the effects, kerosene will be affected most; with a percentage increase in the price of electricity, mean household expenditure on kerosene decreases by ETB 1.93. The recent increase in electricity tariff probably decreases the consumption of kerosene while increasing that of firewood.

Habtamu (2001) indicated that consumption of charcoal is negatively correlated with kerosene and electricity consumptions, implying that these fuels are used as substitutes for charcoal. However, the correlation estimate for fuel wood was found to be positive suggesting that charcoal and fuel wood are not substitutes; they rather seem to be complements. A percentage increase in the price of charcoal decreases the consumption of firewood and dung cakes by $0.61 \%$ and $6.95 \%$, respectively, while increasing that of kerosene by $2.53 \%$; the consumption of electricity is not affected. When charcoal becomes more expensive, households mainly shift towards kerosene; a percentage rise in the price of charcoal increases mean household expenditure on kerosene by ETB 2.28.

Bereket et al. (2002) showed a percentage increase in the price of firewood increases the demand for charcoal and electricity by $3.10 \%$ and $0.59 \%$, respectively, while decreasing that of kerosene by $0.63 \%$. Since both the budget share as well as the elasticity of charcoal is relatively high, the results suggested that as the price of firewood increases households mainly shift towards charcoal; and while the mean budget share of other fuels is changed by less than one ETB, that of charcoal 
increase by ETB 2.68 for a percentage increase in the price of firewood. The budget share of charcoal is much higher than kerosene. The elasticities also indicate that the effects on the modern fuels, kerosene and electricity, is quite different result; an increase in the price of firewood encourages the consumption of electricity but discourages the use of kerosene.

The pricing policy has an important bearing effect on patterns of energy demand by changing relative energy prices. Particularly electricity and kerosene are the two energy resources with active government interventions in Ethiopia. Subsidized fuels are made cheaper relative to unsubsidized ones encouraging the use of the former. Energy prices are subsidized either to give access to the poor or for other purposes like slowing down the rate of deforestation. Kerosene was also explicitly subsidized but the subsidy become beyond the capacity of the government and recently the price has increased towards international market price. The price of electricity was below long run marginal cost in Ethiopia, however, recently the tariff has increased significantly.

Bereket et al. (2002) showed alternative costs of using electricity are significantly higher than other fuels of mean energy expenditures for urban poor households. Mean energy expenditure of poor and non-poor households is only $14 \%$ and $35 \%$ of the cost of using electricity compared to other sources. This result is an indication that electricity is by far too expensive for the average urban poor household. LPG is a more expensive fuel as compared to kerosene. Kerosene not seems to be affordable by all urban households including the poor.

\subsection{Energy per unit of cost}

The choice of kerosene depends, among other things, on its relative cost, their availability and convenience. The availability of evidence indicates that kerosene prices have been rapidly increased as a result of international oil price crisis. In the past, fuel wood prices were almost comparable to those of modern fuels. Ethiopia was experiencing kerosene fuel price rises in excess of general inflation rate.

The demand for fuels depends on their nominal price. However, $1 \mathrm{~kg}$ of fuel wood produces a lot less energy compared to the equivalent quantity of kerosene and such condition will entail comparison of prices based on their energy content rather than nominal prices. Low-quality fuels (e.g. firewood) that burn less efficiently when used, and so more is required to perform the same task. The purpose of evaluating the energy content per unit cost is to standardize the true value of household fuels. 
In order to standardize the price to common unit we need to convert nominal price to energy content in MJ per unit of cost (MJ per ETB). Conversion factors used to calculate energy content per unit of weight for each source of fuel is given below.

Basic density of wood $=500 \mathrm{~kg} / \mathrm{m}^{3}$

Energy content of fuel wood (air-dried) $\equiv 14.5 \mathrm{MJ} / \mathrm{kg}$

Energy content of fuel wood $\equiv 7250 \mathrm{MJ} / \mathrm{m}^{3}$

Energy content of charcoal $\equiv 29 \mathrm{MJ} / \mathrm{kg}$

Energy content of kerosene $\equiv 36.7 \mathrm{MJ} /$ litre

Table 10 indicates that kerosene is becoming more expensive fuel than charcoal and fuel wood. Despite its inconvenience, fuel wood has highest energy content per unit of cost. The low energy costs that the poorer households spend on charcoal and fuel wood indicate its less cost relative to commercial fuel such as kerosene, which have low energy content per unit of cost. The amount of energy the household received per unit of ETB is declining over time in Ethiopia. In 2006 the household received 8.91 Mega Joule per unit cost of one ETB (see Table 10).

Table 10: Nominal and energy content price of fuels in Addis Ababa

\begin{tabular}{ccccccc}
\hline \multirow{2}{*}{ Year } & \multicolumn{3}{c}{ Nominal price (in ETB) } & \multicolumn{3}{c}{ Mega Joule(MJ) per ETB } \\
\cline { 2 - 7 } & $\begin{array}{c}\text { Firewood } \\
\text { per } \mathbf{~ m}^{\mathbf{3}}\end{array}$ & $\begin{array}{c}\text { Charcoal } \\
\text { per kg }\end{array}$ & $\begin{array}{c}\text { Kerosene } \\
\text { per litre }\end{array}$ & Firewood & Charcoal & Kerosene \\
\hline 2001 & 79.88 & 1.00 & 2.00 & 90.8 & 29.0 & 18.4 \\
2002 & 92.76 & 1.06 & 2.00 & 78.2 & 27.4 & 18.4 \\
2003 & 102.65 & 1.45 & 2.00 & 70.6 & 20.0 & 18.4 \\
2004 & 112.85 & 2.15 & 2.00 & 64.2 & 13.5 & 18.4 \\
2005 & 130.21 & 2.10 & 3.00 & 55.7 & 13.8 & 12.2 \\
2006 & - & - & 4.12 & - & - & 8.91 \\
\hline
\end{tabular}

Source: CSA (2001-2005), except for EBF price.

* User changed nominal price to energy content per unit cost using conversion factors.

Quality of fuels increases from firewood, charcoal, kerosene, LPG, to electricity. But, the nominal price of kerosene has been increasing since last year. The local kerosene price has increased by $37 \%$ in 2006 due to current oil price crisis in international market. Within 2001-2005 the nominal price of wood and charcoal has increased by $63 \%$ and $110 \%$, respectively. Energy content per unit cost of fuels declined as we go from firewood, charcoal, to kerosene. Fuel wood has the highest energy content per unit cost, charcoal the second and kerosene the lowest. 
In general, energy content per unit cost has declined over the last five years for all fuels. It has declined for the last five years for fuel wood, charcoal and kerosene by 39, 52 and 52\%, respectively. The highest decline observed is for kerosene and charcoal. Kerosene now becomes more expensive than fuel wood as well as charcoal. However, the amount of energy received per unit cost is becoming smaller over time for charcoal and kerosene. The closest gap observed was at 2005. After 2006 Kerosene become the most expensive fuels among wood, charcoal and kerosene. Even if fuel wood has the lowest quality, it is the cheapest energy source among these fuels and that is why poor households preferred to consume it.

\section{Recommendation}

The demand projection has quite important information for business decision-making in the future. Generally the central part and Eastern regions occupy the highest market share next to Addis Ababa and should be given the highest priority for kerosene distributions and investment.

The demand for kerosene is growing proportionally with per capita income. Kerosene is highly income elastic commodity. Kerosene is becoming the most expensive commercial fuel. Kerosene is also price elastic, implying price increase will lead to a significant reduction in demand for kerosene.

Ethiopia is heavily dependent on petroleum import. The country imports all of its petroleum fuels requirements. Oil security is a matter of key concern to policymakers because kerosene price is strictly increasing in the international market. The opportunity cost of increasing kerosene imports needs to be carefully examined in light of alternatives energy sources (e.g. renewable energy). Kerosene fuel began in the early 1980 s as a long term means to address urban energy demand and to relief pressures on biomass supplies shortage has now become one of the Ethiopian major foreign exchange expenditure. The pattern of future demand for kerosene should be modified by economic measures taken to reduce the severe cost burden on the balance of payment without affecting the advantage of kerosene to arrest the rate of deforestation. In this regard, renewable energy resources should be given the highest priority for investment. One of such investment area is ethanol production from sugar factories.

The opportunity cost of continued high kerosene imports needs to be carefully examined in light of alternatives (e.g. renewable energy). Renewable energy resources should be given the highest priority. The pattern of future demand for kerosene should be modified by practical and economic measures taken to reduce 
the severe cost burden of imported oil in the balance of payment and to arrest the rate of deforestation of forests.

The development of commercial fuels is highly capital intensive. And energy enters into all productive sectors of the economy as a universal input. Efficient use of resources and long term sustainability are the two important issues of economic panning. Besides, future growth in the energy sector has to be environmentally sustainable. At the same time, over all energy intensity of the economy should be designed on the account of progressive substitution of primary non-commercial biomass energy by efficient commercial sources. There should be a room for substitution of biomass by other products such as electricity, natural gas and other renewable source of energy.

Ethiopia is reasonably well endowed with energy resources, particularly hydroelectricity and other renewable energy sources. There are extensive rivers and tributaries that could provide a large hydro-electric power. These resources can play a catalytic role in sustaining Ethiopia's energy development. The country, however, faces difficulties with commercial energy supplies, particularly electricity supply.

The government's subsidy on kerosene has gradually eroded through its consecutive increase in price. The government may also consider the use of other fiscal mechanisms in order to increase access to modern energy services especially to the poor and to satisfy future energy use goals. However, this will be done with care to avoid introducing structural distortions into the market. Measures should also be taken to ensure that modern energy sources are readily available in rural areas.

The entry of multiple players into the market should be encouraged. Distribution of kerosene shall be fully open to the private sector. Investment shall be based on economic and financial criteria considering open access to the network, balanced domestic supply and environmental impacts. 


\section{References}

Barnes DF, and Qian I. (1992). Urban interfuel substitution, energy use, and equity in developing countries: Some preliminary results. The World Bank, Washington, DC, USA.

Bereket, Almaz J. and Elias M. (2002). Affordability of modern fuels and patterns of energy demand in urban Ethiopia. African Energy Policy Network 295.

CEPPE (Cooking Efficiency Program and Planning in Ethiopia) (1987). Ethiopian Rural Energy Development and Promotion Centre (EREDC).

CSA (Central Statistical Authority of Ethiopia) (1998b). The 1994 population and housing census of Ethiopia. Results for Amhara region, Analytical Report. Volume II. CSA, Addis Ababa, Ethiopia. 267 pp.

Eckholm E. (1984). Fuelwood: The energy crisis that won't go away. Earthscan, London, UK.

EELPA (Ethiopian Electric Power Authority) (1987). Annual report in 1987

EFAP (Ethiopian Forestry Action Program) (1994). Addis Ababa, Ethiopia.

EPC (Ethiopian Petroleum Corporation) (1995). Annual report,

FAO (Food and Agriculture Organization of the United Nations) (2001). FAO country report of Ethiopia. The forestry section in 2020,

Filmer D and Pritchett L. (1996). Environmental degradation and the demand for children: searching for vicious circle. Policy Research Working Paper 1623. World Bank, Washington, DC, USA.

Habtamu Tadesse (2001). Determinants of kerosene consumption in Ethiopia. MA thesis, Institute of Economics, Makerere University, Makerere, Uganda.

Karekezi S and Majoro L. (1999). Energy and environment linkages in African cities. Regional Workshop on Energy and Environment Linkages in African Cities, Nairobi, Kenya, United Nations Centre for Human Settlement.

Leach $G$ and Mearns (1989). Beyond the woodfuel crisis: People, trees and land in Africa. Earthscan, London, UK.

NBE (National Bank of Ethiopia) (2001-2004). Quarterly reports.

Sokona Youba (2005). Energy in sub-Saharan Africa. Helio International, Rio Report.

UNDP (United Nations Development Programme) (1995). Ethiopia energy assessment. The World Bank, Washington, DC, USA. 